\title{
Corrigendum
}

\section{Corrigendum to "Quantitative Detection of miRNA-21 Expression in Tumor Cells and Tissues Based on Molecular Beacon"}

\author{
Qingxin Liu, ${ }^{1,2}$ Jialong Fan, ${ }^{3}$ Chuang Zhou, ${ }^{2}$ Liqun Wang, ${ }^{2}$ Bin Zhao, ${ }^{1}$ Haibin Zhang $\mathbb{D},{ }^{1}$ \\ Bin Liu, ${ }^{3}$ and Chunyi Tong (D) $^{3}$ \\ ${ }^{1}$ College of Veterinary Medicine, Nanjing Agricultural University, Nanjing, Jiangsu 210095, China \\ ${ }^{2}$ Jiangsu Vocational College of Agriculture and Forestry, Jurong, Jiangsu 212400, China \\ ${ }^{3}$ College of Biology, Hunan University, Changsha, Hunan 410082, China
}

Correspondence should be addressed to Chunyi Tong; freeradical00@163.com

Received 22 August 2019; Accepted 29 August 2019; Published 22 January 2020

Copyright (C) 2020 Qingxin Liu et al. This is an open access article distributed under the Creative Commons Attribution License, which permits unrestricted use, distribution, and reproduction in any medium, provided the original work is properly cited.

In the article titled "Quantitative Detection of miRNA-21 Expression in Tumor Cells and Tissues Based on Molecular Beacon" [1], there was an error in Figure 3 as miR21-m3 should run slower than miR21 because the molecular weight of miR21-m3 is a little bigger than miR21. The corrected version of Figure 3 is given as follows.

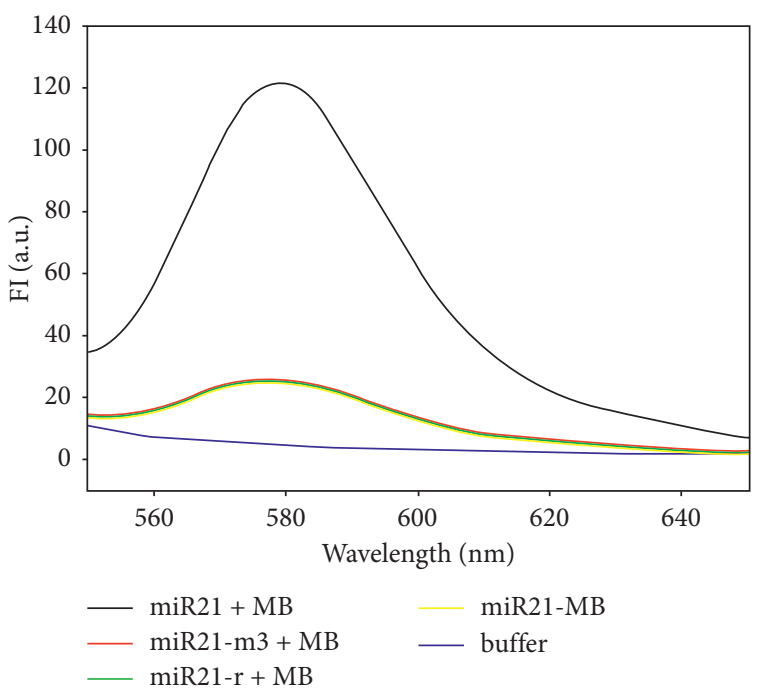

(a)

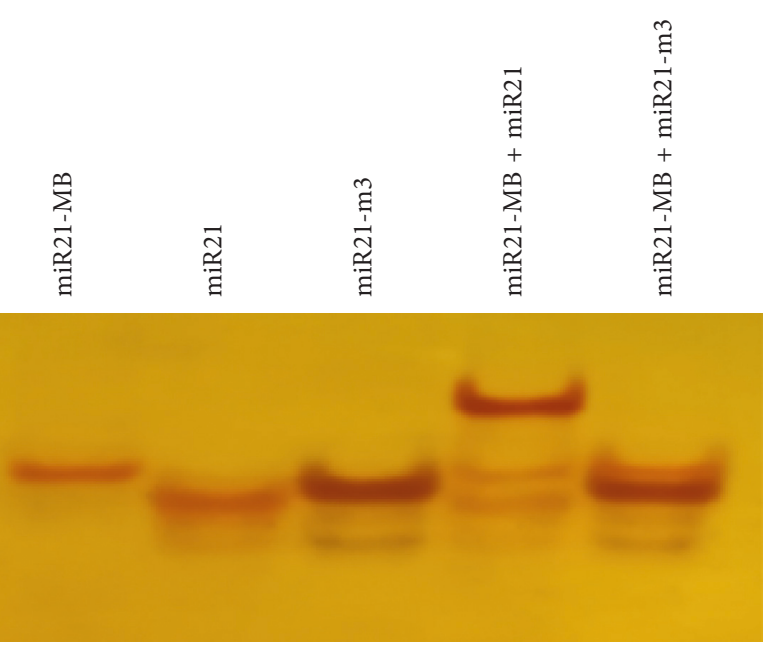

(b)

FIGURE 3: The specificity assay of MB with target by fluorescence spectrometry (a) and polyacrylamide gel electrophoresis staining by silver (b). 


\section{References}

[1] Q. Liu, J. Fan, C. Zhou et al., "Quantitative detection of miRNA-21 expression in tumor cells and tissues based on molecular beacon," International Journal of Analytical Chemistry, vol. 2018, Article ID 3625823, 7 pages, 2018. 

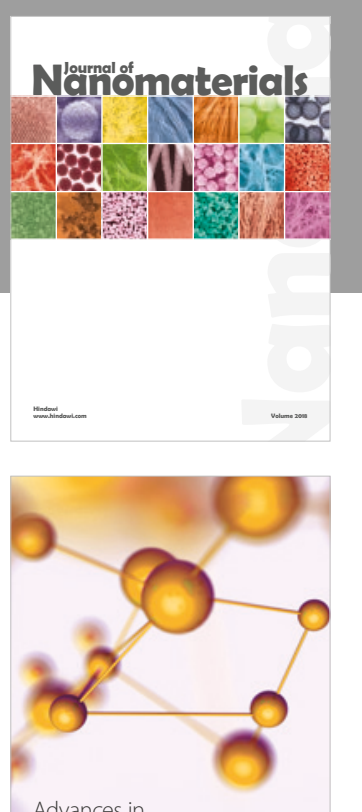

Physical Chemistry
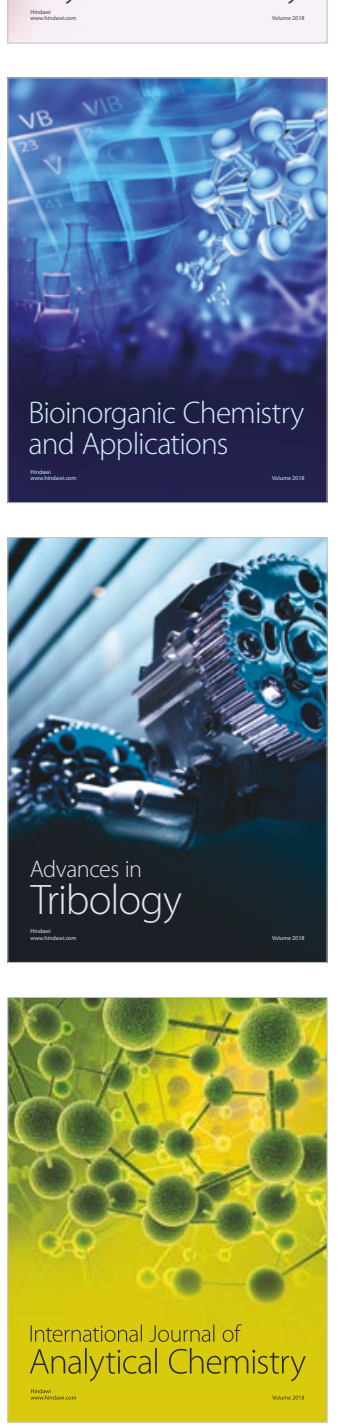

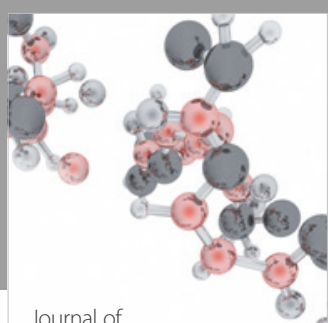

Analytical Methods

in Chemistry

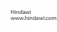

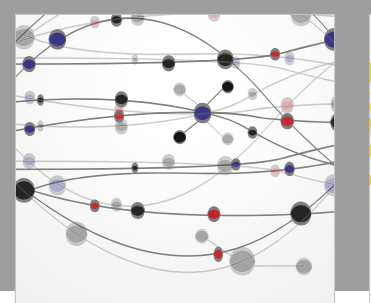

The Scientific World Journal

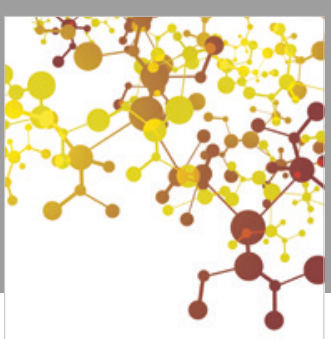

Journal of

Applied Chemistry
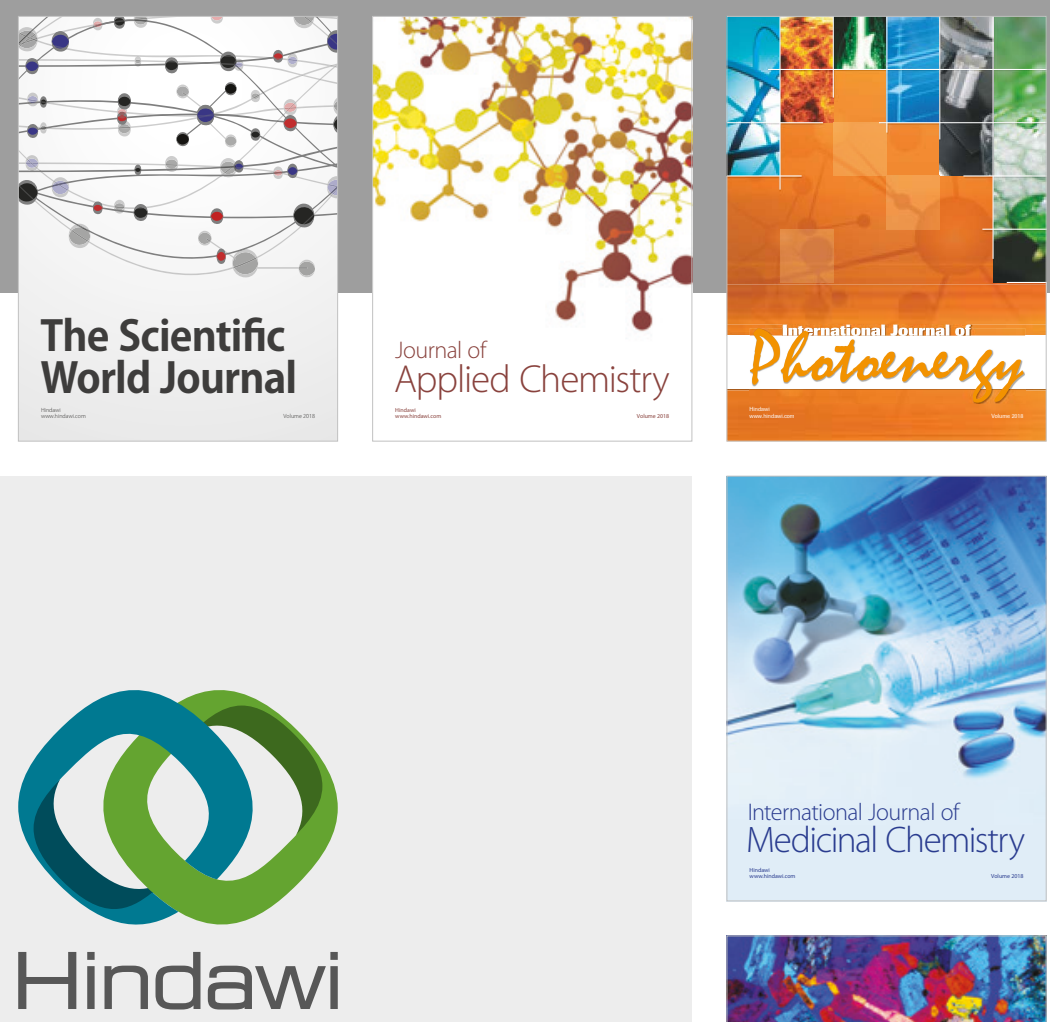

Submit your manuscripts at

www.hindawi.com
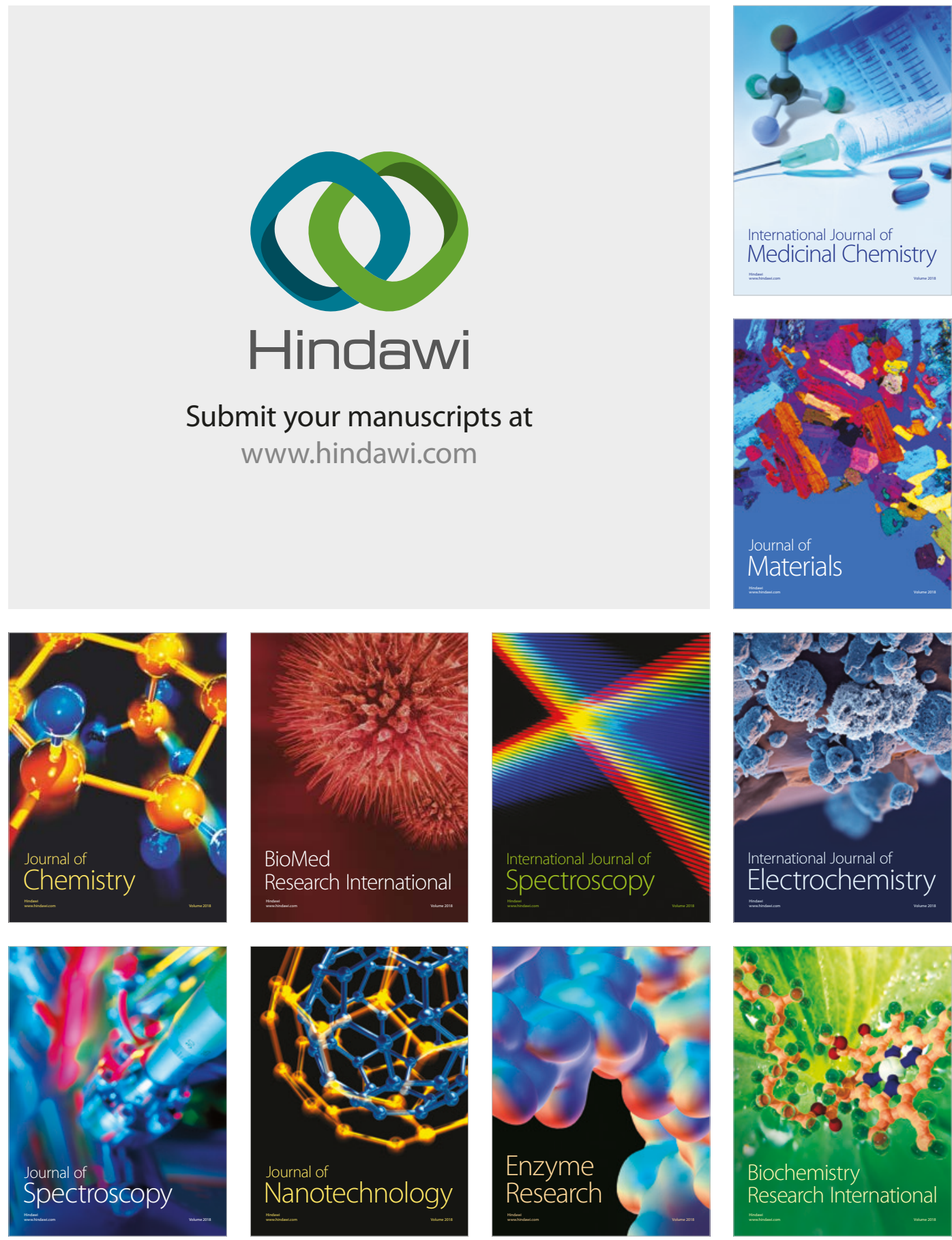
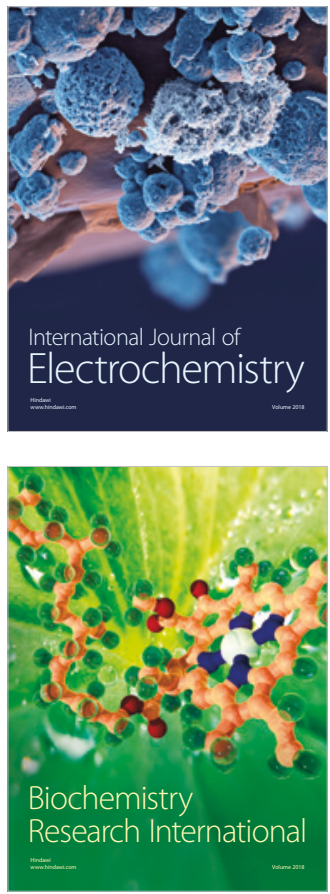